\title{
Predictors of accelerated decline in lung function in adult-onset asthma
}

\author{
Hanneke Coumou ${ }^{1}$, Guus A. Westerhof ${ }^{1}$, Selma B. de Nijs ${ }^{1}$, \\ Aeilko H. Zwinderman ${ }^{2}$ and Elisabeth H. Bel ${ }^{1}$
}

Affiliations: ${ }^{1}$ Dept of Respiratory Medicine, Academic Medical Centre, University of Amsterdam, Amsterdam, The Netherlands. ${ }^{2}$ Dept of Clinical Epidemiology, Biostatistics and Bioinformatics, Academic Medical Centre, University of Amsterdam, Amsterdam, The Netherlands.

Correspondence: Hanneke Coumou, Dept of Respiratory Medicine, F5-260, Academic Medical Centre, University of Amsterdam, PO Box 22700, 1100 DE Amsterdam, The Netherlands.

E-mail: h.coumoudamc.uva.nl

@ERSpublications

Exhaled nitric oxide and BMI predict accelerated decline in FEV1 in adults with new-onset asthma http://ow.ly/1yDz30hE5YE

Cite this article as: Coumou H, Westerhof GA, de Nijs SB, et al. Predictors of accelerated decline in lung function in adult-onset asthma. Eur Respir J 2018; 51: 1701785 [https://doi.org/10.1183/13993003.017852017].

ABSTRACT Little is known about the prognosis of adults with new-onset asthma. Cross-sectional studies suggest that these patients may exhibit accelerated decline in forced expiratory volume in $1 \mathrm{~s}$ $(\mathrm{FEV} 1)$. However, risk factors for accelerated decline in lung function have not yet been identified.

We aimed to identify these risk factors in a prospective 5-year follow-up study in 200 adults with newly diagnosed asthma. In the current study, clinical, functional and inflammatory parameters were assessed annually for 5 years. Linear mixed-effects models were used to identify predictors.

Evaluable lung function sets of 141 patients were available. Median (interquartile range) change in postbronchodilator FEV1 was $-17.5(-54.2$ to +22.4$)$ mL per year. Accelerated decline in FEV1 was defined by the lower quartile of decline ( $>54.2 \mathrm{~mL}$ per year). Nasal polyps, number of blood and sputum eosinophils, body mass index, and level of exhaled nitric oxide were univariably associated with decline in lung function. Only the latter two were independently associated. Using cut-off values to identify patients at highest risk showed accelerated decline in FEV1 in all patients with combined exhaled nitric oxide fraction $(F \mathrm{NO}) \geqslant 57 \mathrm{ppb}$ and body mass index $(\mathrm{BMI}) \leqslant 23 \mathrm{~kg} \cdot \mathrm{m}^{-2}$.

We conclude that adults with new-onset asthma with both high levels of exhaled nitric oxide and low $\mathrm{BMI}$ are at risk of accelerated decline in lung function.

This article has supplementary material available from erj.ersjournals.com

Received: Aug 312017 | Accepted after revision: Nov 232017

Support statement: This study was funded by GlaxoSmithKline (SAS117256). Funding information for this article has been deposited with the Crossref Funder Registry.

Clinical trial: This study is registered at www.trialregister.nl with identifier number NTR1846.

Conflict of interest: Disclosures can be found alongside this article at erj.ersjournals.com

Copyright @ERS 2018 


\section{Introduction}

Asthma is a heterogeneous disease comprising several sub-phenotypes with different clinical, inflammatory and functional characteristics $[1,2]$. Age at disease onset appears to be an important distinctive feature of these sub-phenotypes, as studies have shown that patients with adult-onset asthma differ in many respects from those in whom asthma started in childhood [3]. As adult-onset asthma covers more than $50 \%$ of new diagnoses of asthma $[4,5]$ this is a clinically important phenotype. Adult-onset asthma is associated with more (persistent) eosinophilic airway inflammation and more chronic sinus disease [6,7]. It has also been suggested both in cross-sectional and longitudinal studies that these patients have a more rapid decline in FEV1 $[8,9]$.

Potential factors that have been shown to contribute to accelerated lung function decline in the general asthma population are smoking [10], recurrent exacerbations [11] and low baseline forced expiratory volume in $1 \mathrm{~s}(\mathrm{FEV} 1)$ [12]. However, severity of inflammation could also be an important contributor by inducing airway remodelling [13].

Early identification of patients at risk of accelerated decline in lung function is important because irreversible airflow obstruction is known to be associated with increased morbidity and mortality [14, 15]. In addition, determining the nature of risk factors could help in identifying the most suitable preventive treatment for a specific patient.

In this study, we hypothesised that patients with adult-onset asthma at risk of an accelerated decline in lung function can be identified at diagnosis. The aim of this study was to identify clinical, functional or inflammatory risk factors of accelerated FEV1 decline in a prospective 5-year study in adults with newly diagnosed asthma.

\section{Methods \\ Subjects}

In total, 200 adults who were included in the ADONIS study (Adult-Onset Asthma and Inflammatory Subphenotypes) were prospectively followed for 5 years. Patients aged 18-75 years old were eligible if they had recently ( $<12$ months) been diagnosed with asthma. Asthma diagnosis was based on typical symptoms with at least $200 \mathrm{~mL}$ and $12 \%$ improvement in $\mathrm{FEV}_{1} \%$ predicted values or presence of airway hyperresponsiveness [16]. Current smoking or a smoking history $>10$ pack-years was allowed if there was no airflow obstruction (FEV1/forced vital capacity $(\mathrm{FVC})<0.7$ ) and normal diffusion capacity (diffusing capacity of the lungs for carbon monoxide, corrected for haemoglobin and alveolar volume $>80 \%$ ). Patients with a history of asthma or chronic airways disease in childhood were excluded. The study was approved by the AMC Medical Ethics Board and registered in the Dutch trial register (NTR1846). All participants provided written informed consent.

\section{Study design}

The study design included seven visits over 5 years. At baseline, patients underwent a comprehensive assessment of clinical, functional and inflammatory parameters. Follow-up occurred at yearly intervals, with one additional follow-up visit after 6 months. At the final visit, all baseline measurements were reassessed.

\section{Study measurements}

At baseline, the following data were collected: demographics; medical history; medication use; asthma control (Asthma Control Questionnaire (ACQ)-6) [17]; standardised pre- and post-bronchodilator spirometry (FEV1 and FVC) [18]; airway hyperresponsiveness, defined as the provocative concentration of methacholine needed to establish a $20 \%$ fall in FEV1 (if no fall was reached, a concentration of $32 \mathrm{mg} \cdot \mathrm{mL}^{-1}$ was used); atopy, defined as $\operatorname{IgE}>0.35 \mathrm{kU} \cdot \mathrm{L}^{-1}$ for at least one out of a set of common aeroallergens (ImmunoCAP, ThermoScientific, Uppsala, Sweden); peripheral blood cell counts; fraction of exhaled nitric oxide (FeNO) (NIOX System, Aerocrine, Sweden) [19]; sputum cell differentials according to international standards [20]; and nasal polyposis, based on nasal endoscopy and/or nasal polypectomy in the history of the patient. At subsequent visits, the parameters of medication use, ACQ, Asthma Quality of Life Questionnaire, exacerbations (defined as courses of oral corticosteroids in the previous follow-up period), post-bronchodilator ( $\mathrm{pb}$ )FEV1, peripheral blood cell counts and FeNO were assessed. At the final visit, all baseline assessments were repeated, with the exception of atopic status and presence of nasal polyposis.

\section{Definition of accelerated decline}

Annual pbFEV1 decline per patient was calculated as the slope of the regression line of the individual pbFEV1 measurements over time. Annual pbFEV1 decline per patient was dichotomised at the lower quartile ( $\leqslant 25$ th percentile). Values below this lower quartile were defined as accelerated decline. 


\section{Statistical analysis}

Data from patients who attended only the baseline visit and had no follow-up data were excluded. A linear mixed-effects model of the longitudinal pbFEV1 values over time ( $\mathrm{mL}$ per year) was used to determine the relationship between the annual pbFEV1 decline and covariates. Change in pbFEV1 over time (years) was modelled as a linear function. Patients' individual intercept and slope over time were included as random effects in the linear mixed-effects model. We assessed whether the slopes of these individual regression lines were different between variable levels by inclusions of interaction terms of the predictor with follow-up time in years in the mixed-effects model.

Univariable mixed models were used to select variables for the multivariable mixed models $(p<0.10)$, containing either continuous or dichotomised predictor variables. Backward selection was used in the multivariable continuous and dichotomised models, and all models we adjusted for baseline pbFEV1 (expressed as $\mathrm{pbFEV}_{1} \%$ of predicted) by including this variable as main effect. Thereafter, exacerbations during follow-up were added to the multivariate model.

Subsequently, receiver operating characteristic analysis based on the results of the mixed effect model was performed with accelerated pbFEV1 decline as outcome. We defined cut-off values of the predictor variables as the threshold with $90 \%$ specificity for each predictor variable.

Statistical significance was set at a p-value of $<0.05$. SPSS software (Version 23; IBM SPSS, Armonk, NY, USA) and Rstudio (Version 1.0.136; Free Software Foundation, Inc., Boston, MA, USA) were used for statistical analyses.

\section{Results}

Of 200 patients included in the study, repeated lung function tests of 141 patients $(71 \%)$ were available over a period of 5 years. The 59 patients with incomplete datasets were more often female $(71 \%$ versus $50 \% ; \mathrm{p}<0.01)$ and used lower doses of inhaled corticosteroids $\left(250 \mu \mathrm{g} \cdot \mathrm{day}^{-1}\right.$ versus $\left.313 \mu \mathrm{g} \cdot \mathrm{day}^{-1} ; \mathrm{p}=0.02\right)$ than the patients with complete datasets (Table E1). Baseline characteristics of the 141 adults with new-onset asthma are shown in table 1. The median time between asthma diagnosis and baseline visit was 2 (interquartile range $1-5$ ) months. The mean \pm SD follow-up time was $4.6 \pm 1.4$ years, with a median of 5

\section{TABLE 1 Baseline characteristics of participating patients}

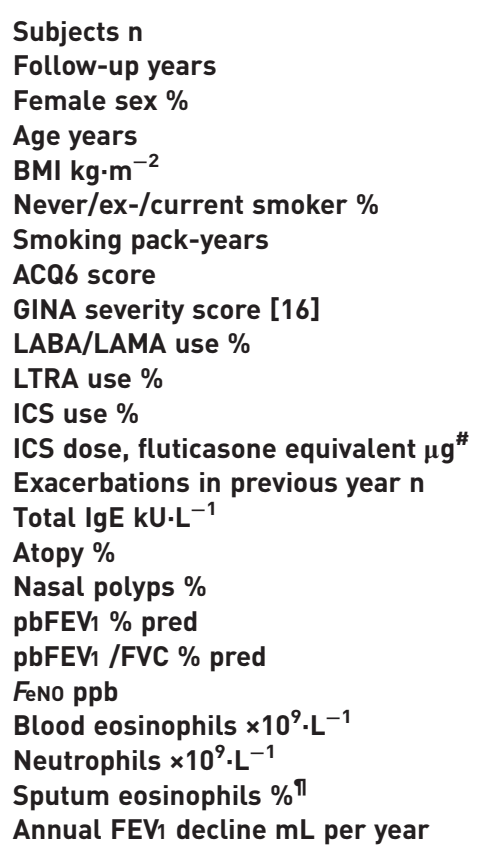

Data are presented as mean \pm SD or median (interquartile range), unless otherwise stated. BMI: body mass index; ACQ: Asthma Control Questionnaire; GINA: Global Initiative for Asthma; LABA: long-acting beta-agonists; LAMA: long-acting muscarinic antagonists; LTRA: leukotriene receptor antagonist; ICS: inhaled corticosteroids; pbFEV1: post-bronchodilator forced expiratory volume in $1 \mathrm{~s}$; FVC: forced vital capacity; $F_{\text {eNO}}$ : fraction of exhaled nitric oxide. ${ }^{\#}$ : reported daily dose; ${ }^{\text {I: }} \mathrm{n}=86$. 
(5-6) visits. The median exacerbation rate was $0(0-0.25)$ per year; $68 \%$ of the patients did not report any exacerbation during follow-up and $19 \%$ experienced only one exacerbation. The median change in pbFEV 1 was $-17.5 \mathrm{~mL}$ per year. The limit of the lower quartile was at $-54.2 \mathrm{~mL}$ per year and the limit for the upper quartile was $+22.4 \mathrm{~mL}$ per year.

\section{Predictors for accelerated lung function decline}

Univariable linear mixed effect analysis showed that the presence of nasal polyps, lower body mass index (BMI), higher numbers of blood eosinophils, higher \% of sputum eosinophils and higher levels of FeNO were significantly associated with a steeper decline in pbFEV1 (table 2, figure 1). Male sex also tended to be associated with a steeper decline in $\operatorname{pbFEV}_{1},(\mathrm{p}=0.08)$. Other variables were not associated with lung function decline.

When all significant $(\mathrm{p}<0.10)$ continuous variables from the univariate analysis were put into a backward selection multivariable model, only higher FeNO and lower BMI were significantly associated with decline in pbFEV 1 , with values of $-0.55 \mathrm{~mL}$ per ppb per year $(\mathrm{p}=0.001)$ and $2.20 \mathrm{~mL}$ per $\mathrm{kg} \cdot \mathrm{m}^{-2}$ per year $(\mathrm{p}=0.049)$, respectively. When the calculated cut-off values of the variables were put into the backward selection multivariable model, FeNO $(\geqslant 57 \mathrm{ppb})$ and BMI $\left(\leqslant 23.05 \mathrm{~kg} \cdot \mathrm{m}^{-2}\right)$ were significantly associated with a change in pbFEV1 of $-37.9 \mathrm{~mL}$ per year $(\mathrm{p}=0.015)$ and $-49.9 \mathrm{~mL}$ per year $(\mathrm{p}=0.003)$, respectively (table 3$)$.

The negative predictive values of $F \mathrm{eNO} \geqslant 57 \mathrm{ppb}$ or BMI $\leqslant 23.05 \mathrm{~kg} \cdot \mathrm{m}^{-2}$ were fairly good, at $77 \%$ and $79 \%$, respectively (table 4 ), while the positive predictive values for $F$ eNO $\geqslant 57 \mathrm{ppb}$ or BMI $\leqslant 23.05 \mathrm{~kg} \cdot \mathrm{m}^{-2}$ were lower, at $45 \%$ and $41 \%$, respectively. However, when $F e N O \geqslant 57 \mathrm{ppb}$ and BMI $\leqslant 23.05 \mathrm{~kg} \cdot \mathrm{m}^{-2}$ were combined, the positive predictive value for accelerated lung function decline was $100 \%$.

When exacerbations were added to the continuous model, BMI and FeNO remained associated with lung function decline, but there appeared to be no association between exacerbations and lung function decline $(\mathrm{p}=0.253)$. In addition, no association was seen in the model using the cut-off variables.

\section{Discussion}

This study shows that in adult patients with new-onset asthma, higher FeNO levels and lower BMI are independently associated with faster decline in FEV1. When we used cut-off values to identify patients at highest risk of accelerated lung function decline, (defined as the lowest quartile of decline in FEV1), it appeared that all patients with combined $F$ eNO $\geqslant 57 \mathrm{ppb}$ and $\mathrm{BMI} \leqslant 23.05 \mathrm{~kg} \cdot \mathrm{m}^{-2}$ showed accelerated decline. No influence on lung function decline of current or former smoking or airway hyperresponsiveness was observed. These results suggest that among adults with new-onset asthma,

TABLE 2 Univariable mixed effect model

\begin{tabular}{|c|c|c|}
\hline & Change in pbFEV 1 mL per year ${ }^{\#}$ & p-value \\
\hline FenO ppb & -0.60 & $<0.001$ \\
\hline BMI $\mathrm{kg} \cdot \mathrm{m}^{-2}$ & 2.96 & 0.011 \\
\hline Presence of nasal polyps (yes) & -33.24 & 0.023 \\
\hline Sputum eosinophils \% & -1.35 & 0.022 \\
\hline Blood eosinophils $\times 10^{9} \cdot \mathrm{L}^{-1}$ & -32.98 & 0.044 \\
\hline Female sex & 20.89 & 0.084 \\
\hline Current/ex-smoker (yes) & -18.98 & 0.126 \\
\hline Age years & -0.65 & 0.128 \\
\hline ACQ6 score & 10.83 & 0.129 \\
\hline GINA severity score[16] & 8.31 & 0.194 \\
\hline Pack-years n & -0.60 & 0.210 \\
\hline No ICS use & -20.63 & 0.214 \\
\hline Exacerbations in previous year $\mathbf{n}$ & -4.82 & 0.300 \\
\hline Neutrophils $\times 10^{9} \cdot \mathrm{L}^{-1}$ & 4.34 & 0.340 \\
\hline Presence of atopy (yes) & -9.46 & 0.440 \\
\hline $\lg \mathrm{E}$ & -0.004 & 0.549 \\
\hline Airway hyperresponsiveness $\mathrm{mg} \cdot \mathrm{mL}^{-1}$ & 0.164 & 0.772 \\
\hline ICS dose, fluticasone equivalent $\mu \mathrm{g}^{\pi}$ & 0.004 & 0.811 \\
\hline \multicolumn{3}{|c|}{$\begin{array}{l}\text { Significant } \mathrm{p} \text {-values are shown in bold. pbFEV1: post-bronchodilator forced expiratory volume in } 1 \mathrm{~s} \text {; FeNO: } \\
\text { fraction of exhaled nitric oxide; BMI: body mass index; ACQ: Asthma Control Questionnaire; GINA: Global } \\
\text { Initiative for Asthma; ICS: inhaled corticosteroids. " : change in pbFEV1 in } \mathrm{mL} \text { per year, per increase in } \\
\text { variable; ๆ: reported daily dose. }\end{array}$} \\
\hline
\end{tabular}



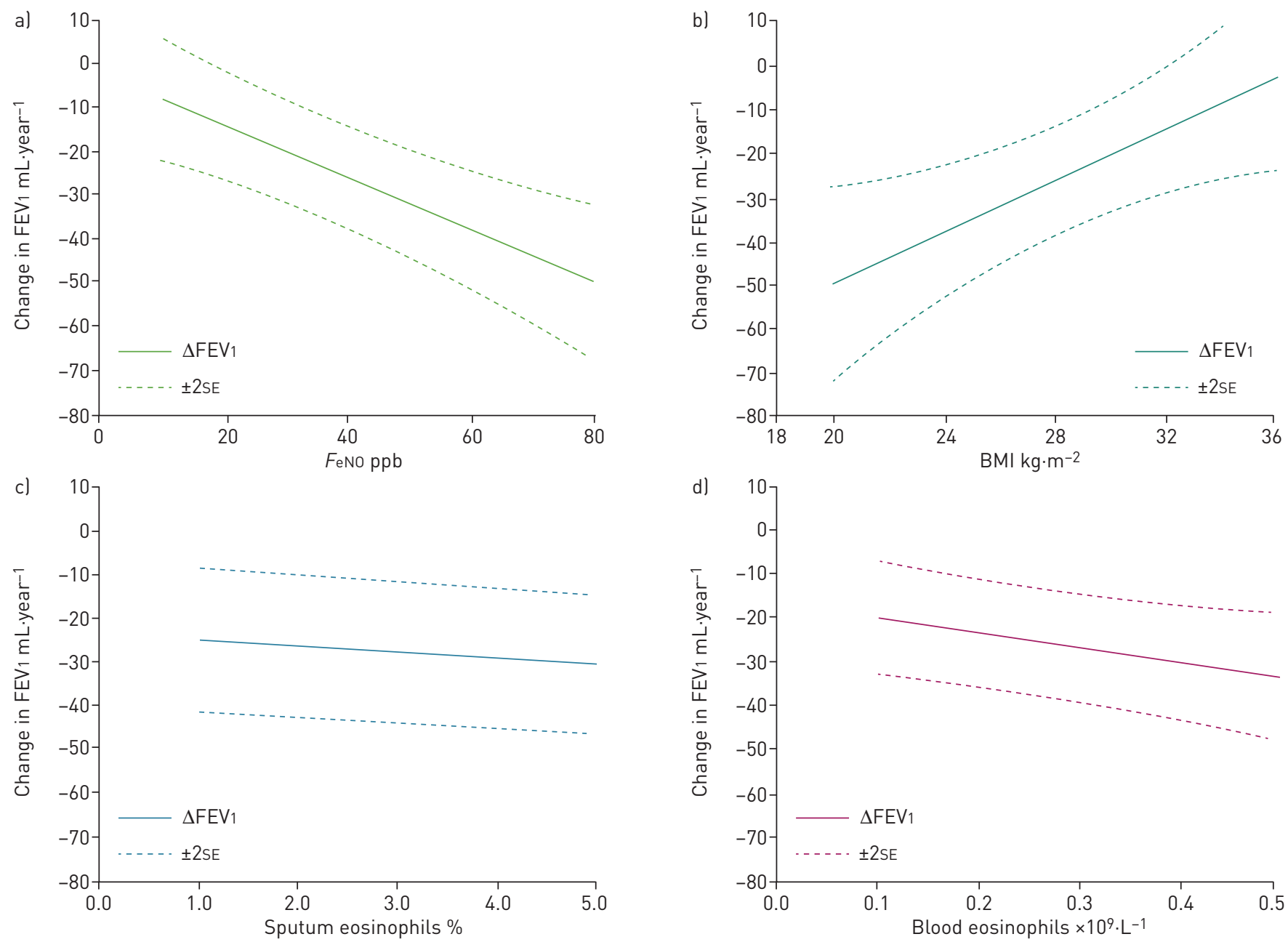

FIGURE 1 Univariable models for forced expiratory volume in $1 \mathrm{~s}$ (FEV1) decline with different biomarkers. a) $F_{\text {eNO }}(p<0.001)$; b) body mass index (BMI) ( $p=0.011)$; c) sputum eosinophils ( $p=0.022)$; and $d$ ) blood eosinophils ( $p=0.044)$. Solid line: change in post-bronchodilator ( $p b) F E V 1$ (mL per year, per increase in biomarker); dotted line: $\pm 2 \mathrm{se}$.

nonobese patients with relatively severe airway inflammation are at highest risk of lung function impairment in the future.

This prospective longitudinal study focused specifically on the prognosis of new-onset asthma in adults, with a special emphasis on the predictive value of clinical, functional and inflammatory markers. One other study in a Finnish adult-onset asthma population reported a smoking history $>10$ pack-years to be associated with accelerated decline in FEV1 [21], which was not confirmed by our data, and might be

TABLE 3 Multivariable mixed effect model with use of cut-off values

Change in pbFEV1 $\mathrm{mL}$ per year"

p-value

\begin{tabular}{|c|c|c|}
\hline $\mathrm{BMI} \leqslant 23.05 \mathrm{~kg} \cdot \mathrm{m}^{-2}$ & -56.80 & 0.002 \\
\hline$F_{e N O} \geqslant 57 \mathrm{ppb}$ & -37.78 & 0.015 \\
\hline Blood eosinophils $\geqslant 0.39 \times 10^{9} \cdot \mathrm{L}^{-1}$ & -24.59 & 0.234 \\
\hline Female sex & 12.69 & 0.272 \\
\hline Sputum eosinophils $\geqslant 6.6 \%$ & 19.17 & 0.564 \\
\hline Presence of nasal polyps (yes) & -10.13 & 0.609 \\
\hline
\end{tabular}

Significant $p$-values are shown in bold. pbFEV1: post-bronchodilator forced expiratory volume in $1 \mathrm{~s}$; BMI: body mass index; FeNO: fraction of exhaled nitric oxide. " : change in pbFEV1 in $\mathrm{mL}$ per year, per increase in variable. 


\begin{tabular}{lcccc} 
TABLE 4 Test characteristics & & & \\
& Sensitivity $\%$ & Specificity $\%$ & PPV $\%$ & NPV \% \\
\hline FeNo $\geqslant \mathbf{5 7} \mathbf{~ p p b}$ & 30 & 88 & 45 & 80 \\
BMI $\leqslant \mathbf{2 3 . 0 5} \mathbf{~ k g} \cdot \mathbf{m}^{-\mathbf{2}}$ & 20 & 91 & 41 & 77 \\
FeNO $\geqslant \mathbf{5 7} \mathbf{~ p p b}$ and BMI $\leqslant \mathbf{2 3 . 0 5} \mathbf{~} \mathbf{~ g} \cdot \mathbf{m}^{-\mathbf{2}}$ & 15 & 100 & 100 & 78 \\
\hline
\end{tabular}

PPV: positive predictive value; NPV: negative predictive value; FeNO: fraction of exhaled nitric oxide; BMI: body mass index.

explained by the low numbers of pack-years and few current smokers in the present study, and our exclusion of patients especially prone to the effects of smoking (i.e. those having $\mathrm{FEV} 1 / \mathrm{FVC}<0.7$ or lowered diffusing capacity of the lung for carbon monoxide). Neither could we confirm increased airway hyperresponsiveness or asthma exacerbation rate to be risk factors of accelerated decline in FEV1, as reported in several but not all previous studies [11, 21-24]. These discrepancies might be due to differences in study population, i.e. the adult-onset asthma population in our study versus the general asthma population in the other studies. This emphasises the importance of taking age at disease onset into consideration in asthma studies [2]. With respect to BMI, results similar to ours were found in one study showing a faster FEV1 decline in nonobese compared with obese patients with adult asthma [25]. Remarkably, in the general population, the opposite result has been described, with an association found between high BMI and lung function decline [26]. High FeNO levels have been associated with excess decline in lung function in previous studies in long-standing adult asthma [27, 28], and our study provides evidence that even at the start of the disease high FeNO levels predict a substantial loss of lung function over the first 5 years.

The strengths of our study are its focus on a relatively underexposed and poorly studied asthma phenotype, the prospective design of the study, and the extensive clinical, functional and inflammatory characterisation of the patients. Further, a robust statistical analysis was possible because of the relatively high visit rate per patient (median attendance: five out of seven visits), and the high percentage of participants in the follow-up study. Indeed, the linear mixed-effects model, in which all available annual lung function measurements were taken into account, guaranteed a realistic and accurate representation of the course of FEV1 decline over 5 years.

Unfortunately, we were not able to obtain adequate sputum cell samples from all patients, and this might have reduced the potential of this biomarker as a predictor. This fits in with the observation that the percentage of eosinophils in sputum was associated with decline in lung function in the univariable but not in the multivariable analysis. This does not apply to blood eosinophils, meaning that, compared with blood eosinophilia, FeNO was more strongly associated with decline in lung function. Our study did not include a control group, which could be regarded as a limitation. However, solid longitudinal data about lung function decline in healthy volunteers $(22 \mathrm{~mL}$ per year) and patients with asthma (38 $\mathrm{mL}$ per year) are available [10]. In the present study, we chose the lower quartile for lung function decline to define accelerated decline in pbFEV1 (54.2 mL per year). Thus, this definition seems to be clinically relevant.

How can we explain the association between high FeNO and accelerated decline in lung function? An obvious explanation would be that patients with high levels of FeNO were not using adequate amounts of anti-inflammatory medications, owing to poor adherence or under-treatment. Inhaled corticosteroids have been shown to decrease FeNO values [29] and prevent deterioration in lung function over time in patients with newly diagnosed asthma [30]. However, when we compared patients with and without accelerated decline in lung function, there was no difference in inhaled corticosteroids dosing, asthma symptoms or airway hyperresponsiveness, implying that high FeNO levels were not associated with poorer asthma control or presence of airway dysfunction, so that there was no clinical reason to assume that patients were not adherent or that they needed an increase in asthma treatment. Another explanation could be that the FeNO levels are caused by nasal polyposis [31]. Although nasal polyposis was not independently associated with loss of lung function, this might be because half of the patients diagnosed with this condition were treated with topical corticosteroids. Therefore, we cannot fully exclude the possibility that nasal polyps are associated with decline in lung function, which would fit with the observation that nasal polyposis is a characteristic of a specific severe adult-onset asthma phenotype [32]. In fact, the high FeNO levels in these patients might reflect a "silent" mechanism leading to loss of lung function. Many studies have shown that high FeNO levels are associated with eosinophilic airway inflammation [33-35], and it is generally accepted that persistent airway inflammation leading to airway remodelling is a cause of accelerated lung function decline [13]. Remarkably, asthma characterised by predominant eosinophilic airway inflammation is 
typically associated with adult-onset asthma and low symptom scores [1], which fits in with our concept that $\mathrm{FeNO}$ is a marker of asymptomatic airway inflammation in this population.

Lower BMI at baseline was independently associated with an accelerated decline in FEV1, which was an unexpected finding, and we can only speculate on possible mechanisms. In previous studies, associations between weight gain and decline in lung function have been observed both in patients with asthma [25] and in the general population $[26,36]$. However, this association was most marked in patients who became obese during the follow-up period [36]. In our study, patients with a low BMI did not become obese; the mean BMI for this group at the 5 year visit was only slightly higher than at baseline. Another possibility might be that patients with a very low BMI have low muscle mass due to lack of exercise or have a mild wasting syndrome related to ongoing inflammation. This fits with our observation that the patients with combined low BMI and high FeNO were at greatest risk of accelerated decline in lung function. Finally, obese and nonobese patients with asthma may represent different asthma phenotypes, not only with respect to clinical and inflammatory mechanisms but also with respect to airway remodelling and long-term prognosis [37, 38]. A recent cluster analysis also points in this direction, showing less lung function decline in obese patients with asthma compared with lean patients [39].

Our study has clinical implications because it provides a new and important role for FeNO in daily practice. Our results suggest that $F$ eNO is an easily measured, noninvasive biomarker of ongoing eosinophilic airway inflammation, even in patients who have controlled disease without exacerbations. It also suggests that a high FeNO level at asthma diagnosis should be taken seriously, especially in patients who have already received initial treatment, as it may reflect ongoing or refractory inflammation and loss of lung function in the long term. FeNO-guided treatment is currently advocated only for adults and children with frequent asthma exacerbations [40,41], but this recommendation is based on studies that have not taken the rate of lung function decline into account. Therefore, studies investigating whether FeNO-guided treatment can prevent accelerated decline in lung function should be high on the research agenda.

In conclusion, our study shows that $F$ eNO is a prognostic biomarker for accelerated decline in lung function in adults with recently diagnosed asthma. In particular, nonobese patients with high FeNo levels seem to be most at risk. High FeNO levels might represent refractory eosinophilic airway inflammation leading to airway remodelling, even in patients with controlled asthma. FeNO might become an important biomarker for clinicians for guiding asthma treatment in daily practice.

\section{Acknowledgements}

We would like to thank all participating patients in the ADONIS study. We thank the medical students for data collection and we thank all the lung function and laboratory technicians who assisted with all the measurements.

\section{References}

1 Haldar P, Pavord ID, Shaw DE, et al. Cluster analysis and clinical asthma phenotypes. Am J Respir Crit Care Med 2008; 178: 218-224.

2 Moore WC, Meyers DA, Wenzel SE, et al. Identification of asthma phenotypes using cluster analysis in the Severe Asthma Research Program. Am J Respir Crit Care Med 2010; 181: 315-323.

3 Wenzel SE. Asthma phenotypes: the evolution from clinical to molecular approaches. Nat Med 2012; 18: 716-725.

4 Sood A, Qualls C, Schuyler M, et al. Adult-onset asthma becomes the dominant phenotype among women by age 40 years. The longitudinal CARDIA study. Ann Am Thorac Soc 2013; 10: 188-197.

5 Kankaanranta H, Tuomisto LE, Ilmarinen P. Age-specific incidence of new asthma diagnoses in Finland. $J$ Allergy Clin Immunol Pract 2017; 5: 189-191.

6 Miranda C, Busacker A, Balzar S, et al. Distinguishing severe asthma phenotypes: role of age at onset and eosinophilic inflammation. J Allergy Clin Immunol 2004; 113: 101-108.

7 Shaaban R, Zureik M, Soussan D, et al. Rhinitis and onset of asthma: a longitudinal population-based study. Lancet 2008; 372: 1049-1057.

8 Ulrik CS, Lange P. Decline of lung function in adults with bronchial asthma. Am J Respir Crit Care Med 1994; 150: 629-634.

9 ten Brinke A, van Dissel JT, Sterk PJ, et al. Persistent airflow limitation in adult-onset nonatopic asthma is associated with serologic evidence of Chlamydia pneumoniae infection. J Allergy Clin Immunol 2001; 107: 449-454.

10 Lange P, Parner J, Vestbo J, et al. A 15-year follow-up study of ventilatory function in adults with asthma. $N$ Engl J Med 1998; 339: 1194-1200.

11 Bai TR, Vonk JM, Postma DS, et al. Severe exacerbations predict excess lung function decline in asthma. Eur Respir J 2007; 30: 452-456.

12 Vonk JM, Jongepier H, Panhuysen CI, et al. Risk factors associated with the presence of irreversible airflow limitation and reduced transfer coefficient in patients with asthma after 26 years of follow up. Thorax 2003; 58: $322-327$.

13 Pascual RM, Peters SP. Airway remodeling contributes to the progressive loss of lung function in asthma: an overview. J Allergy Clin Immunol 2005; 116: 477-486.

14 Hansen EF, Phanareth K, Laursen LC, et al. Reversible and irreversible airflow obstruction as predictor of overall mortality in asthma and chronic obstructive pulmonary disease. Am J Respir Crit Care Med 1999; 159: 1267-1271. 
15 Bumbacea D, Campbell D, Nguyen L, et al. Parameters associated with persistent airflow obstruction in chronic severe asthma. Eur Respir J 2004; 24: 122-128.

16 Global Initiative for Asthma. Global strategy for asthma management and prevention 2002. Available from: http:// ginasthma.org Date last accessed: September 2016.

17 Juniper EF, O'Byrne PM, Guyatt GH, et al. Development and validation of a questionnaire to measure asthma control. Eur Respir J 1999; 14: 902-907.

18 Miller MR, Hankinson J, Brusasco V, et al. Standardisation of spirometry. Eur Respir J 2005; 26: 319-338.

19 Dweik RA, Boggs PB, Erzurum SC, et al. An official ATS clinical practice guideline: interpretation of exhaled nitric oxide levels ( $F$ eNO) for clinical applications. Am J Respir Crit Care Med 2011; 184: 602-615.

20 Paggiaro PL, Chanez P, Holz O, et al. Sputum induction. Eur Respir J 2002; 20: Suppl. 37, 3s-8s.

21 Tommola M, Ilmarinen P, Tuomisto LE, et al. The effect of smoking on lung function: a clinical study of adult-onset asthma. Eur Respir J 2016; 48: 1298-1306.

22 Rijcken B, Schouten JP, Xu X, et al. Airway hyperresponsiveness to histamine associated with accelerated decline in FEV1. Am J Respir Crit Care Med 1995; 151: 1377-1382.

23 Peat JK, Woolcock AJ, Cullen K. Rate of decline of lung function in subjects with asthma. Eur J Respir Dis 1987; 70: 171-179.

24 O'Byrne PM, Pedersen S, Lamm CJ, et al. Severe exacerbations and decline in lung function in asthma. Am J Respir Crit Care Med 2009; 179: 19-24.

25 Marcon A, Corsico A, Cazzoletti L, et al. Body mass index, weight gain, and other determinants of lung function decline in adult asthma. J Allergy Clin Immunol 2009; 123: 1069-1074.

26 Chen Y, Horne SL, Dosman JA. Body weight and weight gain related to pulmonary function decline in adults: a six year follow up study. Thorax 1993; 48: 375-380

27 van Veen IH, Ten Brinke A, Sterk PJ, et al. Exhaled nitric oxide predicts lung function decline in difficult-to-treat asthma. Eur Respir J 2008; 32: 344-349.

28 Matsunaga K, Hirano T, Oka A, et al. Persistently high exhaled nitric oxide and loss of lung function in controlled asthma. Allergol Int 2016; 65: 266-271.

29 Kharitonov SA, Yates DH, Barnes PJ. Inhaled glucocorticoids decrease nitric oxide in exhaled air of asthmatic patients. Am J Respir Crit Care Med 1996; 153: 454-457.

30 O’Byrne PM, Pedersen S, Busse WW, et al. Effects of early intervention with inhaled budesonide on lung function in newly diagnosed asthma. Chest 2006; 129: 1478-1485.

31 Galli J, Montuschi P, Passali GC, et al. Exhaled nitric oxide measurement in patients affected by nasal polyposis. Otolaryngol Head Neck Surg 2012; 147: 351-356.

32 Amelink M, de Groot JC, de Nijs SB, et al. Severe adult-onset asthma: A distinct phenotype. J Allergy Clin Immunol 2013; 132: 336-341.

33 Jatakanon A, Lim S, Kharitonov SA, et al. Correlation between exhaled nitric oxide, sputum eosinophils, and methacholine responsiveness in patients with mild asthma. Thorax 1998; 53: 91-95.

34 Berry MA, Shaw DE, Green RH, et al. The use of exhaled nitric oxide concentration to identify eosinophilic airway inflammation: an observational study in adults with asthma. Clin Exp Allergy 2005; 35: 1175-1179.

35 Silkoff PE, Lent AM, Busacker AA, et al. Exhaled nitric oxide identifies the persistent eosinophilic phenotype in severe refractory asthma. J Allergy Clin Immunol 2005; 116: 1249-1255.

36 Pistelli F, Bottai M, Carrozzi L, et al. Changes in obesity status and lung function decline in a general population sample. Respir Med 2008; 102: 674-680.

37 Al-Alwan A, Bates JH, Chapman DG, et al. The nonallergic asthma of obesity. A matter of distal lung compliance. Am J Respir Crit Care Med 2014; 189: 1494-1502.

38 Beuther DA, Weiss ST, Sutherland ER. Obesity and asthma. Am J Respir Crit Care Med 2006; 174: 112-119.

39 Ilmarinen $\mathrm{P}$, Tuomisto LE, Niemela $\mathrm{O}$, et al. Cluster analysis on longitudinal data of patients with adult-onset asthma. J Allergy Clin Immunol Pract 2017; 5: 967-978.

40 Petsky HL, Kew KM, Turner C, et al. Exhaled nitric oxide levels to guide treatment for adults with asthma. Cochrane Database Syst Rev 2016; 9: CD011440.

41 Petsky HL, Kew KM, Chang AB. Exhaled nitric oxide levels to guide treatment for children with asthma. Cochrane Database Syst Rev 2016; 11: CD011439. 